\title{
Creating a global climate for pediatric cardiac care
}

\author{
Jacques G Leblanc \\ Vancouver, Canada
}

$\mathrm{P}$ ediatric heart diseases include congenital and acquired heart diseases. Congenital heart disease (CHD) is defined as a structural or functional heart disease present from birth and encompasses a large variety of heart malformations. Acquired heart disease is defined as a disease affecting the heart after birth, the most common being rheumatic heart fever. Without early recognition, diagnosis, and treatment, many infants and children will die in their first month of life from a few percent in developed countries to well over $50 \%$ in developing countries. ${ }^{[1]}$ As political, social, and financial systems vary widely from developed to developing countries, access to pediatric cardiac care differs and creating a global climate for pediatric cardiac care becomes imperative.

\section{Millennium Development Goals}

At the United Nations Millennium Summit in 2000, leaders from 191 nations established what became the Millennium Development Goals (Table 1). ${ }^{[2]}$ The eight goals address specific issues such as poverty, hunger, education, child and maternal mortality, diseases like diarrhea, malaria, HIV/AIDS, and environmental problems such as water and sanitation. Ninety million children per year have diarrhea with a mortality of $5 \%$ to $15 \%$. Up to $40 \%$ of the population of certain areas in Africa are HIV positive. Malaria affects millions of children. The world population in 1980 was 3.2 billion people, with the largest group in Africa, India and China. This figure is expected to reach 9 billion people in 2030. The population of children is growing as well with 1.9 billions children under 15 years of age in 2004, again mainly in Africa and India. With 160 million

Author Affiliations: British Columbia Children's Hospital, 4480 Oak Street, Suite AB307, Vancouver, BC V6H 3V4, Canada (Leblanc JG)

Corresponding Author: Jacques G Leblanc, MD, FRCSC, Clinical Professor, British Columbia Children's Hospital, 4480 Oak Street, Suite AB307, Vancouver, BC V6H 3V4, Canada (Tel: +1-604-875-3165; Fax: +1-604-875-3159; Email: jleblanc@cw.bc.ca)

babies born every year, it is an immense challenge to control infant mortality (10 million per year under the age of 5 years). For example, neonatal mortality is $1 / 1000$ in Japan and 1/20 in Northern Africa. Similarly, maternal mortality is 2 per 100 births in North Africa while 0.4 per 1000 births in Japan. ${ }^{[2-8]}$

While pediatric heart diseases are not explicitly included in the Millennium Development Goals, accomplishing some of the goals will have a direct impact on children with heart disease in developing countries. Lowering maternal and child mortality rates, improving vaccination and sanitation, training and increasing the number of skilled health care professionals, improving health care infrastructure can benefit children with congenital and acquired heart disease.

\section{Status of cardiac surgery}

Global health expenditure is a large part of the GDP in the Western Nations like North America, Europe and Japan but down to a fraction of the GDP in the developing world like Africa. Many reasons can be invoked for this disparity in health expenditure such as: private versus public funding varying from country to country, free standing pediatric cardiac center versus a combined adult and pediatric cardiac center, geographical location with cardiac centers in big cities and no regional centers, unstable versus stable political systems affecting social stability, and specific health care policies pertaining to each country. ${ }^{[9]}$ These have resulted in great disparities in access to pediatric cardiac care. ${ }^{[10]}$ The United States have 25000 neonates born with CHD per year but with 120 pediatric cardiac

Table 1. 2000 Millennium Development Goals from the United Nations Millennium Summit

Goal 1: eradicate extreme poverty and hunger by half

Goal 2: achieve universal primary education

Goal 3: promote gender equality and empower women

Goal 4: reduce child mortality by $75 \%$

Goal 5: improve maternal health/reduce mortality by $75 \%$

Goal 6: combat HIV/AIDS, malaria, diarrhea, and other diseases

Goal 7: ensure environmental sustainability, safe drinking water and sanitation by $50 \%$

Goal 8: develop a global partnership for access to drugs and care 
centers which operate on 24000 children with CHD per year. Conversely, Brazil also sees 24000 neonates born with CHD per year, but with only 60 pediatric cardiac centers, which operate on 9000 children with CHD per year. India and China, together have 312000 neonates born with CHD per year, but with 34 pediatric cardiac centers combined, which care for over 66000 children per year. Except for four centers in South Africa, few children get cardiac care on the entire African continent (Table 2).

Treatment for congenital heart disease is currently out of reach to the majority of the world's population for a number of reasons: expense of treatment, poor access to health care, under-developed health systems, lack of resources and personnel, poor governance, corruption and war. Many countries struggle to meet their country's basic primary health needs, therefore making it impossible to provide tertiary-level cardiac care and treatment. There are other reasons for inadequate pediatric cardiac treatment. One of them is simple lack of awareness of CHD with many births at home without proper supervision, a very small number of CHD detected at birth because of no medical supervision and/ or inadequate training of the physicians/pediatricians. Too often referrals are delayed because of limited knowledge of natural history, inaccurate diagnosis, lack of awareness about available facilities. With limited pediatric cardiac facilities, families need to travel far away with limited resources, loss of income and difficulty in staying in a foreign city. Many families may seek advice from unqualified doctors, complicating the situation.

\section{International strategies}

In the developing world, the burden of poverty, lack of economic growth and stability and poor governance continue to present the necessary investment in healthcare, infrastructure and staff training needed to build sustainable health care systems. Congenital heart disease is often not considered a priority. Strategies to provide help to these countries come from the international community, through numerous nonprofit and non-governmental organizations. It includes transport of children to developed countries, organizing surgical missions, and establishing a cardiovascular center. ${ }^{[11]}$ Many organizations have started by bringing children from poor countries to advanced cardiac centers in developed countries. However helpful it may be, transporting and treating a child in advanced centers can be prohibitively expensive. Most importantly, only a few children can be treated with such program. Therefore, organizations started to send pediatric cardiac specialist teams with their equipment to underdeveloped countries to treat children with CHD and perform cardiac operations. However, while the teams accomplish their goals of treating children with CHD, a short mission may not have enough time to train local doctors in complicated surgical techniques. The host hospital may not have the equipment and money to maintain a program. The health care professionals may not have enough time for training to build a program, often complicated by language barriers. Most organizations can only fund a few missions per year and relatively few children can be treated with each visit while the intentions for sustainability is not realized.

The best way to reach and care for many children with CHD is to bring care to their local environment. Many organizations and some governments have begun to fund training for cardiac surgeons, cardiologists, anesthetists, technicians and nurses at advanced medical centers. These professionals can receive specialized training in pediatric cardiology and surgical techniques and return home to share their new knowledge. Scheduled visits from the advanced training centers can support the professionals with newly acquired skills to maintain their skills and even to progress. A number of organizations have taken an additional step toward helping developing countries by building facilities and encouraging facilities to become regional centers. These regional centers can serve as referral centers where a pediatric cardiac unit with highly trained personnel and appropriate sophisticated equipment would serve in treating a large population of children with CHD. This strategy combines both the efforts of bringing children to pediatric cardiac units for advanced care and, also a way to train highly skilled doctors, surgeons, technicians and nurses who can maintain their competency. ${ }^{[10,12]}$ Sustained international support and strong partnership are necessary for the creation and continuation of regional surgical centers.

Table 2. World challenges in pediatric cardiac care

\begin{tabular}{lllcrr}
\hline Country & Pop & $\begin{array}{c}\text { Live } \\
\text { Birth }\end{array}$ & $\begin{array}{c}\text { Children } \\
\text { CHD per yr }\end{array}$ & $\begin{array}{c}\text { Pediatric } \\
\text { CVT centers }\end{array}$ & $\begin{array}{r}\text { CHD } \\
\text { cases }\end{array}$ \\
\hline USA & $300 \mathrm{mil}$ & $4.1 \mathrm{mil}$ & 25000 & 120 & 24000 \\
Russia & $142 \mathrm{mil}$ & $1.48 \mathrm{mil}$ & 15000 & 26 & 10600 \\
Japan & $127 \mathrm{mil}$ & 908000 & 7200 & 60 & 9000 \\
Brazil & $190 \mathrm{mil}$ & $3.1 \mathrm{mil}$ & 24000 & 46 & 9000 \\
China & $1.3 \mathrm{bil}$ & $16.5 \mathrm{mil}$ & 132000 & 20 & 60000 \\
India & $1.1 \mathrm{bil}$ & $28 \mathrm{mil}$ & 180000 & 14 & 6500 \\
Canada & $33 \mathrm{mil}$ & 335000 & 2800 & 8 & 2550 \\
Turkey & $72 \mathrm{mil}$ & $1.1 \mathrm{mil}$ & 11500 & 25 & 4000 \\
Egypt & $79 \mathrm{mil}$ & $1.9 \mathrm{mil}$ & 15000 & 3 & 2100 \\
Australia & $21 \mathrm{mil}$ & 265000 & 2200 & 6 & 1900 \\
South Africa & $46 \mathrm{mil}$ & 725000 & 6000 & 4 & 1200 \\
\hline Pop: Poput & & &
\end{tabular}

Pop: Population; mil: million; bil: billion; CVT: cardiovascular and thoracic. 


\section{KISS approach}

With such a daunting task of treating millions of children with congenital and acquired heart diseases in the developing world, non-profit and non-governmental organizations as well as governments of these countries, still need to focus on maximizing resources to reach the most children. A "KISS approach"_-keep it simple and safe-has important value. First, to identify where to establish a regional center requires collection of data on current services in the country, on-site visit to assess the feasibility of the project, establish ongoing funding. A minimum of 1 year is required before starting an open heart surgery program, during which time, not only personnel is trained abroad, but onsite infrastructure such as operating theater, intensive care unit, medical diagnostic unit, cardiology area, is being built, equipment being purchased. On its return, the trained personnel need to put in place protocol and check all equipment and material before starting the program. Simple steps can be kept in mind to maximize the scarce resources. Invasive investigations can be reduced with improved echocardiographic diagnosis and skills. Anesthesia, minimizing monitoring open heart surgical techniques and cardiac perfusion should be used in the view to facilitate early extubation and to help nursing staff in their active role of post operative care. Economy of scale can be obtained on hardware and disposable equipment by using locally produced equipment. Despite hard work, tremendous effort, and cohesive team approach, the success of a new program requires 3 to 5 years commitment to sustain growth, and achieve results. ${ }^{[10-13]}$

\section{Human resources crisis in health care}

The late WHO director, Dr. Lee Jong-Wook said: "There is a chronic shortage of well-trained health workers. The shortage is global but most acutely felt in the countries that need them most". There is a worldwide shortage of well-trained nurses, technicians and allied health workers, despite increasing numbers of trainees in the developed world. ${ }^{[14]}$ Multiple reasons are cited: aging population with more demands for care, population growth, aging health care workers group leaving the work force, governmental policies on health care. ${ }^{[15]}$ Therefore, developed countries are struggling to meet their own health care demands and they contribute to the global human resource crisis by hiring from the developing and under-developed countries. It certainly provides opportunities for these countries' health care workers to leave an unattractive environment at home to leave their families and to work abroad. The following issues are cited as the most common reasons for health care workers to leave their home country: low income, poor working conditions, lack of resources to work effectively, unsuitable and unsafe working environment, lack of jobs, limited career development and poor economic stability. Conversely, factors attracting health care workers are high pay, better working conditions, better resourced health care systems, career opportunities, political stability and a better life. ${ }^{[16]}$

Managing migration of health care workers who are departing the already burdened health care system of their countries is a complex issue. The very same reasons by health care workers who are leaving their countries are also specific opportunities for these countries to work at improving their health care system. Retaining health workers can be done by providing adequate salary, something as simple as clear water, key supplies and working equipment for patient care, clear job descriptions and supervision and at least some form of continuing education. The approach of training local professionals abroad and inside their home countries may need to change, such as establishing another level of health care professionals by decreasing their training but still providing enough education to these clinical officers to reach front line rural sick children. It is a controversial approach, but certainly a viable option for the developing countries. Can one restrain health workers from leaving? It is certainly impossible to hold health workers and prevent them from looking for better opportunities, but options such as providing a minimum year of work in your country if trained abroad, or simply paying back your country for your training abroad are possible to explore. Unfortunately, these options are difficult to implement, can be costly and have not materialized yet. Lastly, several countries in the developed world have instituted codes of conduct regarding the ethical recruitment of health care workers from developing countries. Private recruitment agencies are discouraged to hire from the developing world but ultimately, the strength of the code of conduct rests upon its enforcement. Despite attempts from health organizations and governments to help alleviate the disparity of health care between the developed and developing or under-developed world, the crisis of migration of health workers remains no matter what. ${ }^{[17]}$

\section{Conclusion}

While children's heart diseases are only one of a multitude of health problems facing under-developed countries, they are linked to many of the other problems. Non-profit and non-governmental organizations are involved in a number of different strategies to treat children with heart disease. Still basic steps are required 
such as increasing awareness of CHD in the general population and amongst pediatricians of developing countries. Optimal utilization of available technology is fundamental with a willingness to share between adult and pediatric cardiac programs so pediatric cardiac programs can be made sustainable. A prioritization of care is mandatory to triage the most number of cases and maximize the number of patients treated. Creation of national databases is a very important step to learn about epidemiology, to plan care and to develop policies and funding. None of this can happen without the active role and coordinated efforts at national level from the governments of these developing countries in an effort to create national health care policy, increase health care spending, improve education and training for health professionals, and address public health care issues. Only when it is in place within the global context of economic and health care disparities will the international community be able to help reduce the prevalence of acquired pediatric heart disease and improve diagnosis and treatment of pediatric congenital heart disease.

Funding: None.

Ethical approval: Not needed.

Competing interest: None.

Contributors: Leblanc JG is the single author of this paper.

\section{References}

1 Thakur JS, Negi PC, Ahluwalia SK, Sharma R. Integrated community-based screening for cardiovascular diseases of childhood. World Health Forum 1997;18:24-27.

2 United Nations 2000. Millenium development goals: UN Millenium Declaration. http://www.un.org/millenniumgoals/ (accessed September 18, 2008).
3 World Bank. www.worldbank.org/data (accessed September 5, 2008).

4 United Nations Development Programs. www.undp.org/reports/ detail (accessed September 10, 2008).

5 World Health Organization, 2005. www.who.int/whr/2005/en (accessed September 15, 2008).

6 Angus Maddison's data. www.ggdc.net/maddison (accessed September 18, 2008).

7 United Nations Population Division. www.un.org (accessed September 9, 2008).

8 Gastner MT, Newman ME. From the cover: diffusion-based method for producing density-equalizing maps. Proc Natl Acad Sci U S A 2004;101:7499-7504.

9 Pezzella AT. International cardiac surgery: a global perspective. Semin Thorac Cardiovasc Surg 2002;14:298-320.

10 Hewitson J, Brink J, Zilla P. The challenge of pediatric cardiac services in the developing world. Semin Thorac Cardiovasc Surg 2002; 14:340-345.

11 Abdulla RI. Congenital heart disease management in developing countries. Pediatr Cardiol 2002;23:481-482.

12 Cohen AJ, Tamir A, Houri S, Abegaz B, Gilad E, Omohkdion S, et al. Save a child's heart: we can and we should. Ann Thorac Surg 2001;71:462-468.

13 Kumar RK, Tynan MJ. Catheter interventions for congenital heart disease in third world countries. Pediatr Cardiol 2005;26:241-249.

14 Vaidyanathan B, Kumar RK. The global burden of congenital heart disease. Congenital Cardiology Today 2005;3:1-10.

15 Mullan F. Doctors and soccer players-African professionals on the move. N Engl J Med 2007;356:440-443.

16 BACH S. International mobility of Health Professional: Brain Drain or Brain Exchange? United Nations University. World Institute for Development Economics. London: Research Paper, 2006: 82.

17 World Health Organization. The global shortage of health workers and its impact, 2006. http://www.who.int/mediacentre/ factsheets/fs302/en/index.html (accessed September 15, 2008).

Received March 2, 2009

Accepted after revision March 31, 2009 